early postoperative period. Provided the diagnosis is established early in the postoperative period, and adequate antituberculosis chemotherapy is instituted, the outcome of joint arthroplasty may not be adversely affected.

No benefits in any form have been received or will be received from a commercial party related directly or indirectly to the subject of this article.

\section{REFERENCES}

Aichroth P, Freeman MAR, Smillie JS, Souter WA. A knee function assessment chart. J Bone Joint Surg [Br] 1978; 60-B:308-9.
Besser MIB. Total knee replacement in unsuspected tuberculosis of the joint. Br Med J 1980;280:1434.

Hardinge K, Cleary J, Charnley J. Low-friction arthroplasty for healed septic and tuberculous arthritis. J Bone Joint Surg [Br] 1979; 61B: $144-7$.

Hecht RH, Meyers MH, Thornhill-Jones M, Montgomerie JZ. Reactivation of tuberculous infection following total joint replacement: a case report. J Bone Joint Surg [Am] 1983; 65-A :1015-6.

Kim YY, Ko CU, Lee SW, Kwak BM. Replacement arthroplasty using the Charnley prosthesis in old tuberculosis of the hip. Int Orthop $1979 ; 3: 81-8$

Wray CC, Roy S. Arthroplasty in tuberculosis of the knee : two cases of missed diagnosis. Acta Orthop Scand 1987; 58:296-8.

\title{
FABELLAR JOINT CAUSING PAIN AFTER TOTAL KNEE REPLACEMENT
}

\author{
LINDSAY LAIRD
}

Case report. A 68-year-old man presented in October 1988 with a four-year history of increasing pain in the right knee. The clinical and radiological signs were consistent with osteoarthritis and the symptoms did not respond to conservative measures.

In January 1989 a cemented press-fit condylar (PFC) total knee replacement (Johnson \& Johnson, Brunswick, New Jersey) was performed. The patient progressed uneventfully and achieved $100^{\circ}$ flexion of the knee.

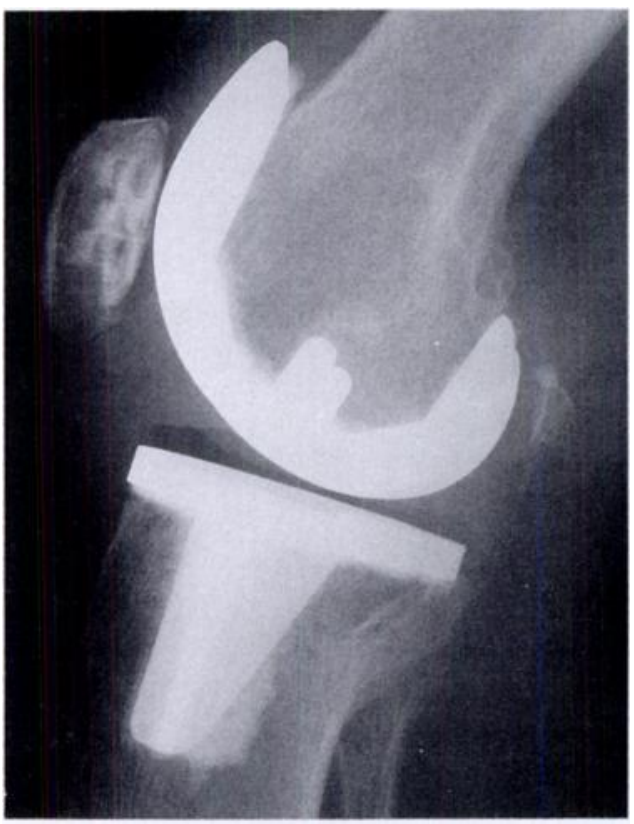

Fig. 1

L. Laird, FRCS, FRACS

386 King Street, Newcastle, New South Wales 2300, Australia.

(C) 1991 British Editorial Society of Bone and Joint Surgery 0301-620X/91/6R28 $\$ 2.00$

J Bone Joint Surg [Br] 1991 ; 73-B: 1007-8.
However, three months postoperatively he complained of pain behind the knee. A hard lump could be palpated in the lateral aspect of the popliteal fossa and pressure on the lump during flexion and extension caused increased pain.

The pain persisted and radiographs, taken at seven months, showed that the fabellar articular surface was parallel to the posterior condyle of the prosthesis (Fig. 1). Manipulation under image intensification confirmed

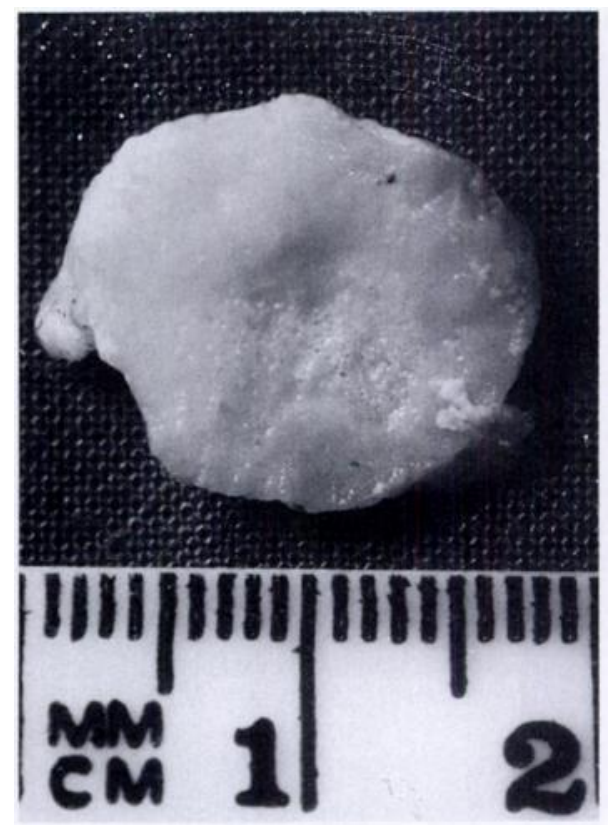

Fig. 2

their close apposition. The fabella did not appear to get caught on the prosthetic components during flexion and extension movements.

A needle was introduced into the fabellar joint under radiographic control and $2 \mathrm{ml}$ bupivacaine was injected 
with immediate relief of pain. Surgical removal of the fabella was later performed through a small posterolateral incision. At operation direct articulation was found between the fabella and the posterior condyle of the prosthesis. The fabella showed macroscopic changes of degeneration of its articular surface (Fig. 2) which was confirmed by histological examination.

The knee functioned without pain some four months later.

Discussion. The fabella is a sesamoid bone often present in the lateral head of the gastrocnemius, close to its origin.

There have been isolated reports of pain secondary to a fracture of the fabella (Sagel 1932) and also from chondromalacia of the fabella (Goldenberg 1956; Zimny and Redler 1972; Weiner and MacNab 1982).

Jaffe, Kuschner and Klein (1988) reported a case of fabellar impingement upon the posterior rim of the tibial component, causing pain after total knee replacement. In this case an arthritic fabella articulated with the posterior condyle of the femoral prosthesis to cause localised pain.

No benefits in any form have been received or will be received from a commercial party related directly or indirectly to the subject of this article.

\section{REFERENCES}

Goldenberg RR. Chondromalacia fabellae. Bull Hosp Joint Dis 1956 ; 17:35-47

Jaffe FF, Kuschner S, Klein M. Fabellar impingement : a cause of pain after total knee replacement. J Bone Joint Surg [Am] 1988; 70A :613-6.

Sagel J. Fracture of sesamoid bones: report of two cases. Am J Surg $1932 ; 18: 507-9$.

Weiner DS, MacNab I. The 'Fabella Syndrome': an update. J Pediatr Orthop 1982; 2:405-8.

Zimny ML, Redler I. An ultrastructural study of chondromalacia fabellae. Clin Orthop 1972; 82:37-44. 